\title{
Improved Control Strategies of Electric Vehicles Charging Station based on Grid Tied PV/Battery System
}

\author{
Abdelilah Hassoune $^{1}$, Mohamed Khafallah ${ }^{2}$ \\ Abdelouahed Mesbahi ${ }^{3}$ \\ Laboratory of Energy and Electrical Systems \\ Hassan II University, ENSEM
}

\author{
Tarik Bouragba ${ }^{4}$ \\ EIGSI Casablanca \\ Casablanca, Morocco
}

\begin{abstract}
In this paper, improved control strategies of a smart topology of EVs charging station (CS) based on grid tied $P V / B a t t e r y$ system are designed and analyzed. The proposed strategies consist of three operating modes i.e. Pv2B; charging a battery storage buffer (BSB) of the CS from solar energy, V2G; discharging an EV battery via grid, and Pv2G; injecting the produced power from PV system into the energy distribution system. However, the BSB is connected to the PV system through a single ended primary inductor converter, the V2G operating mode is emulated by an EV lithium-ion battery tied to the grid via a high frequency full bridge inverter and a bidirectional dc/dc converter. The aim of this work is to improve the energy efficiency of the CS by using a hybrid energy system. Simulation studies are performed in Matlab/Simulink in order to operate the proposed solar CS with multiple control strategies of each case scenario based on a CS management algorithm (CSMA). To provide credible findings of this research, a low power prototype is developed in order to validate the proposed CSMA and its associated controls.
\end{abstract}

Keywords-Component; Electric vehicle charging station; solar energy; battery storage buffer; electrical grid; charging station management algorithm

\section{INTRODUCTION}

The environmental challenges and the predicted shortage of fossil fuels have made the electric vehicles (EVs) more involved in mobility sector. Yet, their development at a wider scale faces enormous constraints, especially with the charging infrastructure by which the charging station (CS) customers would require high charging power rate within a short duration time [1,2]. However, the trend toward clean and renewable energy sources (RESs), opens up a new field where a hybrid energy source will support the quick changes in power demand with less reliance on the fossil fuels. Several publications have appeared in recent years demonstrating and documenting the feasibility of novel approaches, which are based on a multisource system gathered RESs with storage buffers [3-6]. In order to store the renewable energy and/or to overcome the power peak situation when superfast charging scenarios are set, numerous considerations must be taken into account as reported in [7]. In practical terms, the electricity distribution systems have multiple energy constraints i.e. a peak power events caused by both, a large number of plugged in EVs and connected residential or commercial alternating current (AC) loads. To frame this restriction, a distribution transformer (DT) would represent the grid, it is tied to the CS in which instantaneous power flow data would be sensed and analysed by the main controller. Recent researchers have proposed optimization methods to treat all the potential deficiencies, for instance, applying a smart scheduling of power on the supply system control to support all the charging operations based on priority levels [8-11].

The solar energy applications have been deployed very fast and drawn much attention as the case of the electric vehicle charging station (EVCS). Yet and in terms of providing a reliable energy source, the photovoltaic system is still occasionally inefficient because of the intermittent nature of solar irradiance. Nonetheless, it is possible to further enhance the PV output power by adopting new effective MPPT algorithms as discussed in [12-14]. The charging station management system (CSMS) proposed in this paper is based on a decision algorithm uses the power sensing stage in order to set the optimal operating mode for the EVCS. In terms of rapidity and stability, the CS performance would be improved using an optimization algorithm of three operating modes. The battery storage buffer (BSB) is representing the CS storage system, and it is equipped with a battery management system (BMS) which lets the CSMS to get instantaneous data i.e., the state of charge (SC) and the voltage/current. This work explores the electrical behaviour of the lithium ion battery via its charging/discharging cycles, based on that, reliable control modes are presented and analysed in detail. Thus, an experimental evaluation has given the study more credibility to draw final conclusions.

This paper is divided as follows. First, a description of the proposed topology and the operating modes are defined in Section II. Next, Section III illustrates simulation studies of the EVCS based grid tied PV/battery system. Section IV analyses experimental results of the architecture. Finally, a conclusion is presented in Section V.

\section{DESCRIPTION OF THE PROPOSED PlATFORM}

Fig. 1 illustrates in detail the solar charging station (SCS) topology, it consists of a grid tied PV array with BSB. The solar power is injected into the station via two paths of energy flow i.e. a charging process of the BSB through a single ended primary inductor converter (SEPIC) based either MPPT 
algorithm to extract the maximum power from solar irradiance or voltage control mode (VCM) to avoid the overload of the connected battery. The second path is transferring electricity into the grid via dc/dc boost converter when there is a surplus of power at the PV stage or when the BSB is fully charged. However, two DC links are established to get the SCS more efficient in which numerous modes of control are implemented i.e. MPPT algorithm, VCM and current control mode (CCM).

In order to expand the research field and to obtain a quite level of profitability for both, the SCS owner and customer, a bidirectional power flow between the EV and the station is considered in the used management approach. The electrical grid is involved in the SCS via a dc/ac inverter based voltage source converter (VSC) control, the aim is to stabilize the DC link voltage via either, the PV system or the connected vehicle battery operated in V2G mode. However, Fig. 3 shows the flowchart of the main algorithm of the CSMS.

The CSMS controls the commutators of each power sources in order to apply the optimal operating mode. Then, the system generates calculated electric pulses for each converter involved in the current scenario. As it can be seen from the proposed algorithm, the presence of at least one EV at the CS will decide which operating mode will be activated either $V 2 G$, or Pv2G and Pv2B. In fact, the rush hours event is a situation when the CS would benefit as much as possible from the high selling price of the injected grid power. The three operating modes are described as follows:

\section{A. Mode-1: Pv2G}

In this mode, there is no EVs plugged in the solar CS. So, at rush hours when the selling price of $\mathrm{kWh}$ from CS to grid is expensive, the PV system will be given high priority to inject its power into the grid via a dc/dc boost converter and a dc/ac inverter, and as results, two power switches will be activated by the CSMS i.e. BoostOn and GridOn. The full charge of BSB will also activate this mode in order to avoid the overloading constraint $\left(\mathrm{SCB}_{\mathrm{SB}}=\mathrm{SC}_{\mathrm{BSB}-\mathrm{M}}\right)$. In the meanwhile, the control strategies provided by the CSMS will set the MPPT algorithm and the voltage source converter in order to drive the $\mathrm{dc} / \mathrm{dc}$ boost converter and the dc/ac inverter, respectively.

\section{B. Mode-2: $P v 2 B$}

In this case scenario, two power switches are activated i.e., SepicOn and BSBOn. The optimization approach of charging the CS battery explores new features in order to benefit from a maximum range of MPPT mode duration, and quick switching into the voltage regulation mode and reciprocally. The three different phases of charging the BSB are illustrated in Fig. 2.

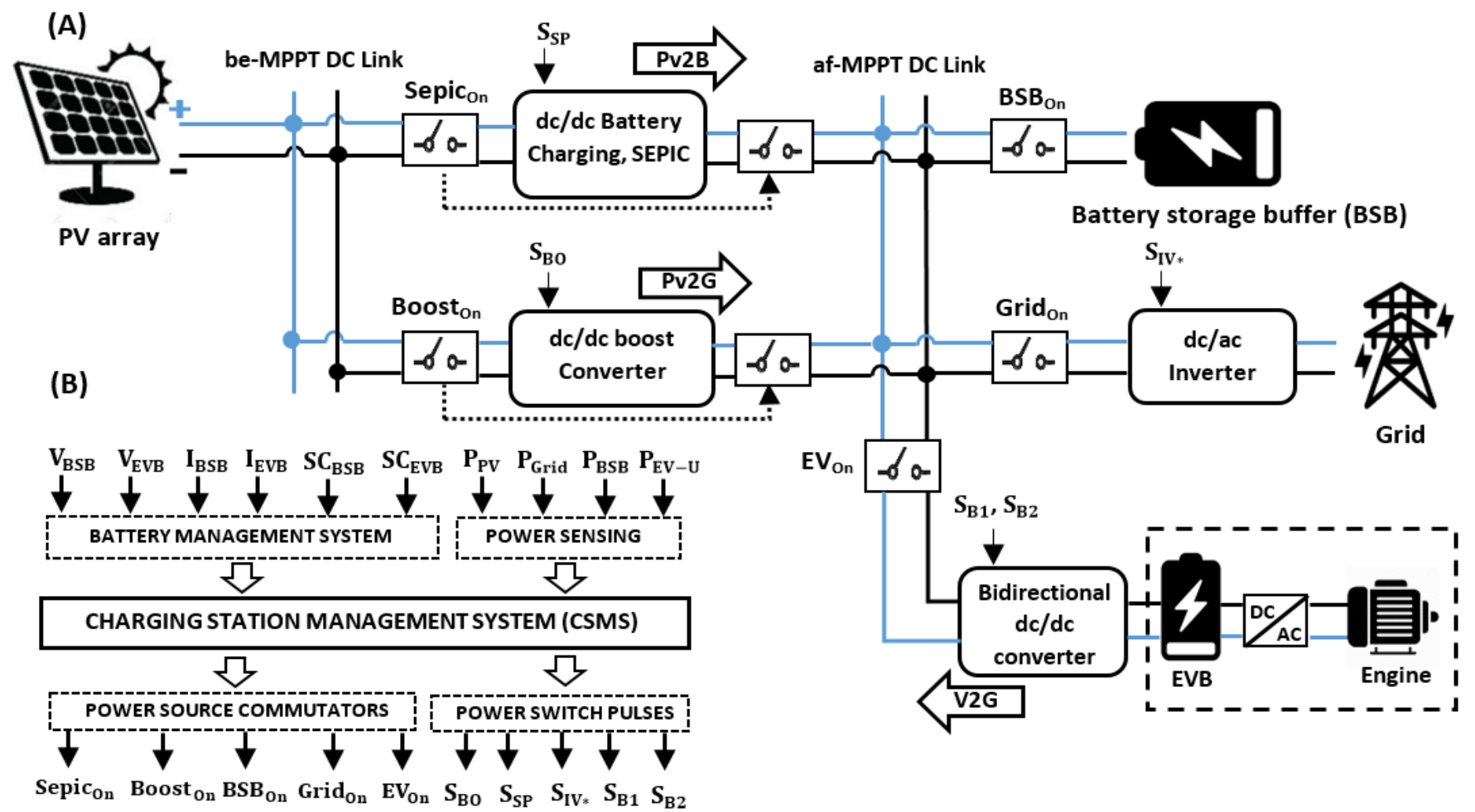

Fig 1. The Proposed Topology (A) Solar Charging Station; (B) Power Management System. 


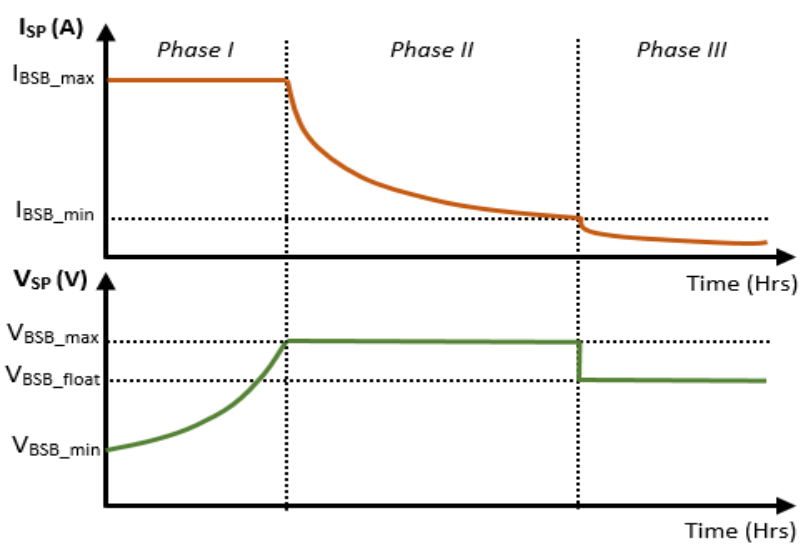

Fig 2. BSB Charging Phases.
The BSB first phase called bulk stage, is controlled by the incremental conductance (INC) MPPT algorithm by dint of the safety margin of the battery voltage which is between the allowed minimum value $\left(\mathrm{V}_{\mathrm{BSB}-\mathrm{min}}\right)$ and the overload maximum value $\left(\mathrm{V}_{\mathrm{BSB}-\max }\right)$. In the meanwhile, the SEPIC output current $\left(\mathrm{I}_{\mathrm{SP}}\right)$ is limited to the maximum deep charge current $\mathrm{I}_{\mathrm{BSB}-\mathrm{max}}$. Once $V_{S P}$ achieved $V_{B S B}$ max, means the battery is now operating in the overcharge phase where the CSMS is switching off the MPPT algorithm and is adjusting the voltage control to the $\mathrm{V}_{\mathrm{BSB}}$ max. The charging current is kept increasing until it falls under $\mathrm{I}_{\mathrm{BSB} \text {-min }}$ where the float charge phase is reached, and in response to this change, the CSMS will readjust its reference voltage to a reduced value ( $\left.V_{B S B-f l o a t}\right)$. This adjustment will avoid the deep self-discharge of the battery by generating a very small charging current [15].

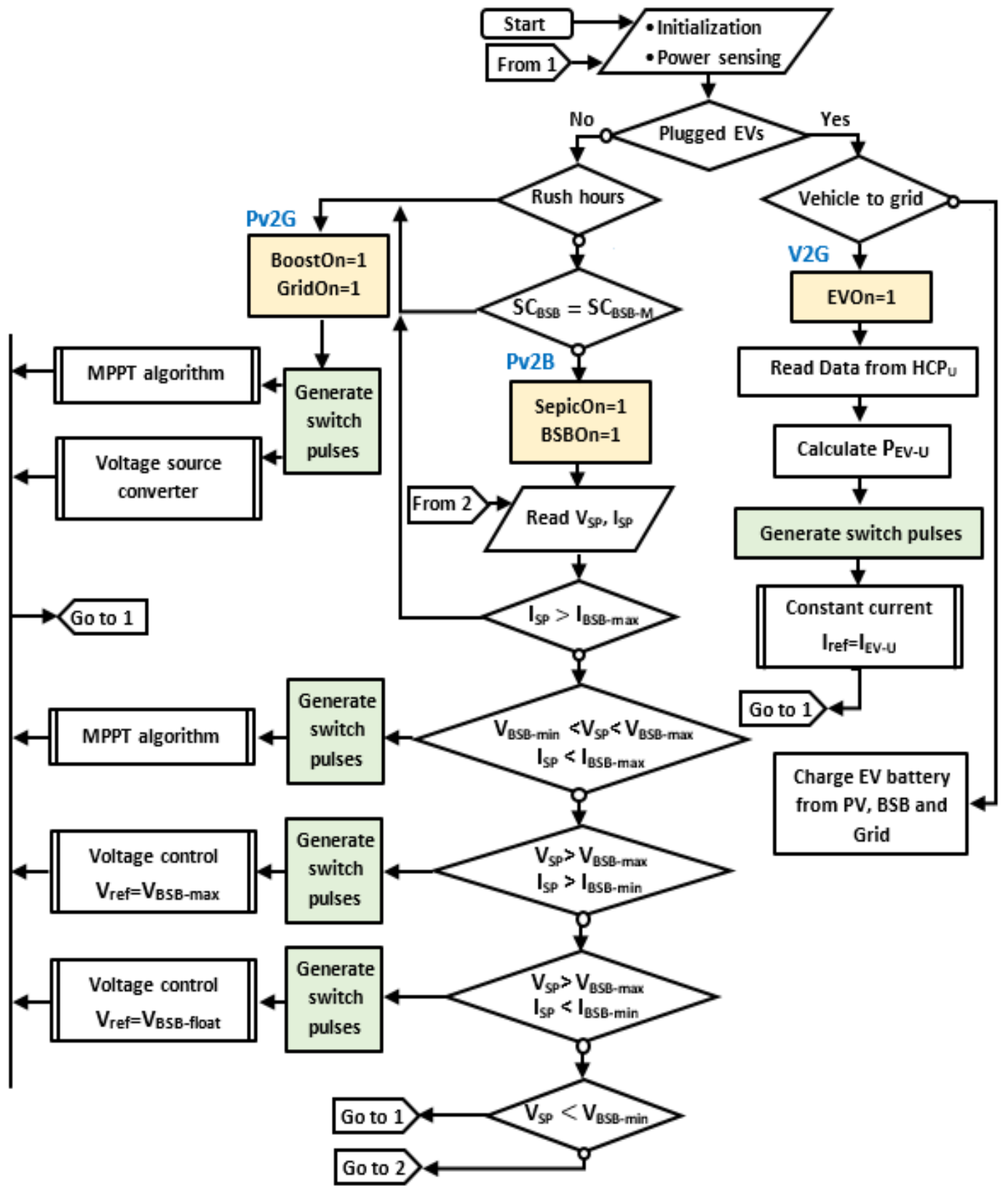

Fig 3. Flowchart of the Charging Station Management Algorithm (CSMA). 


\section{Mode-3: $V 2 G$}

Once an EV battery is plugged into a CS outlet, the CSMS will activate the EVOn and will extract the data from the human control panel of each vehicle user $\left(\mathrm{HCP}_{\mathrm{U}}\right)$.

The power to be injected into the grid from EV battery is expressed as follows:

$P_{E V-U}=\frac{\left(S C_{E V B}-S C_{E V B^{*}}\right) \times B C_{E V B}}{P T_{E V}}$

Where $\mathrm{P}_{\mathrm{EV}-\mathrm{U}}$ is the injected power from an $\mathrm{EV}$ battery, $\mathrm{SC}_{\mathrm{EVB}}$ is the initial state of charge (SC) of a battery, $\mathrm{SC}_{\mathrm{EVB}} *$ is the final $\mathrm{SC}$ set by the vehicle user, $\mathrm{BC}_{\mathrm{EVB}}$ is the battery capacity of the $\mathrm{EV}$ and $\mathrm{PT}_{\mathrm{EV}}$ is the plugged time. The management system will calculate and update the reference current used to drive the bidirectional charger switches as expressed in the following equation:

$I_{E V-U}=\frac{P_{E V-U}}{V_{E V B}}$

Where $\mathrm{I}_{\mathrm{EV}-\mathrm{U}}$ is the reference current set by the CSMS, and $\mathrm{V}_{\mathrm{EVB}}$ is the voltage of an EV battery. The control of the battery discharger consists of two kinds of strategy i.e., constant voltage and constant current [16-18]. When a vehicle battery is connected, it would be recommended at first to start the discharging process with a constant voltage control, and then to switch the control to a constant current $\left(\mathrm{I}_{\mathrm{ref}}=\mathrm{I}_{\mathrm{EV}-\mathrm{U}}\right)$. Fig. 4 depicts the battery discharger operating under a constant current control, a PI controller is used to regulate the margin error between the discharging current and its reference value, followed by a pulse width modulation block to generate the required pulses i.e., $S_{\mathrm{B} 1}$ and $\mathrm{S}_{\mathrm{B} 2}$ [19-21].
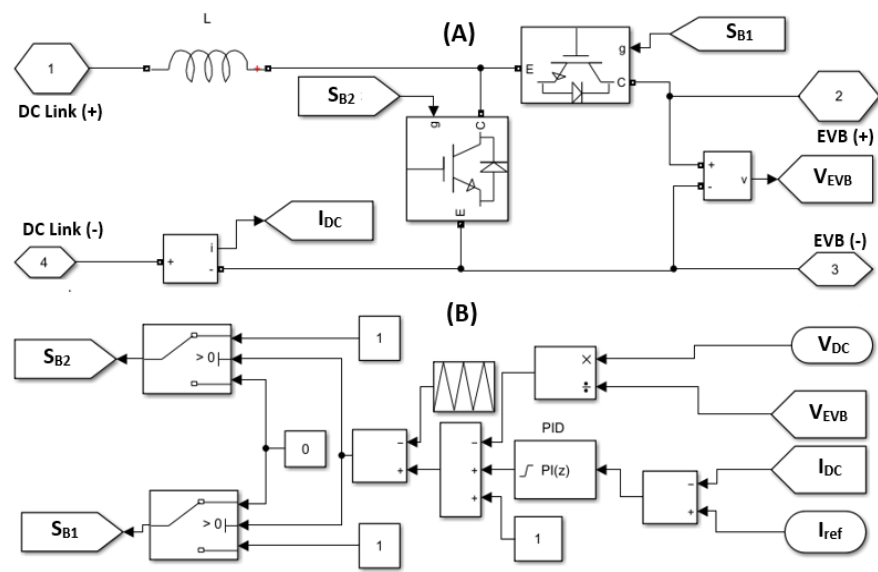

Fig 4. EV Battery Discharger (A) Bidirectional dc/dc Converter (B) Constant Current Control.

\section{Simulation Results}

The simulation study of the proposed topology is designed through a $7.68 \mathrm{kWp}$ ISF-240 PV system prototype, in $(8 \times 4)$ configuration series/parallel, respectively. The af-MPPT DC link voltage is adapted at $500 \mathrm{~V}$ in order to ensure an eventual power injection into the energy distribution system. Thus, the grid is connected via a ac/dc inverter in order to operate the SCS in V2G mode. Fig. 6 illustrates the modelled block diagram in Matlab/Simulink.

To frame the control strategies, the system has been modelled and designed on Matlab/Simulink software, which is carried out three case scenarios:

- Case 1 (Pv2B): BSB charging mode via SEPIC controlled by MPPT algorithm/VCM.

- Case 2 (Pv2G): Power injection mode into grid from solar energy via a boost converter and a dc/ac inverter controlled by a MPPT algorithm and a VSC control, respectively.

- Case 3 (V2G): Vehicle to grid mode via a bidirectional $\mathrm{dc} / \mathrm{dc}$ converter and a dc/ac inverter controlled by a constant current control and a VSC control, respectively.

The proposed block diagram is developed to emulate a part of a CS. However, the simulation is based on multiple scenarios, in which the previous cases will be tested. Fig. 5 depicts the adopted climatic scenario.

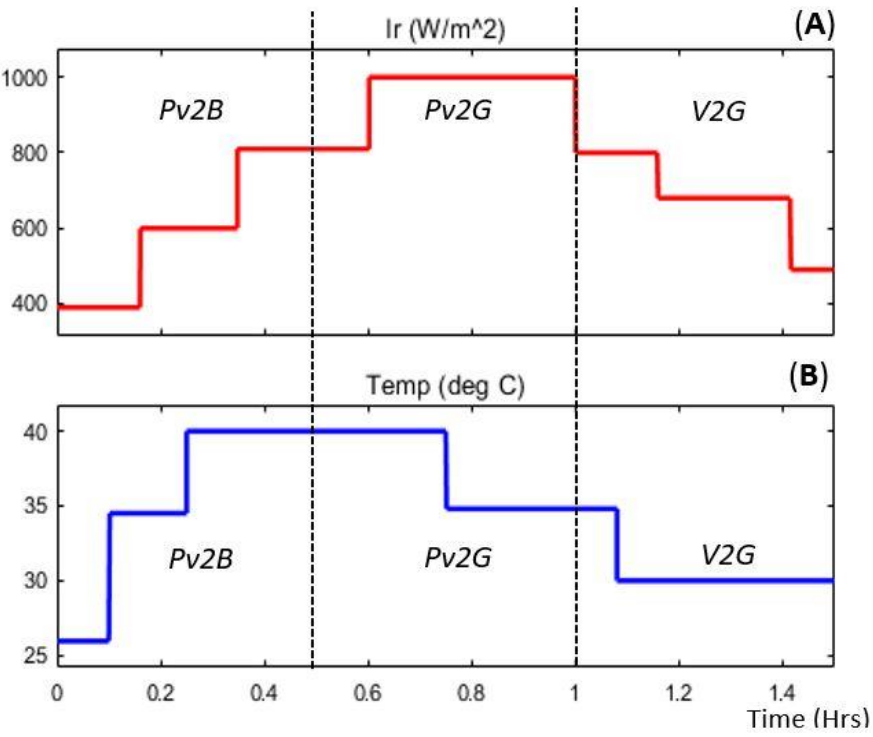

Fig 5. Climatic Scenario Versus Time (A) Irradiation; (B) Temperature. 


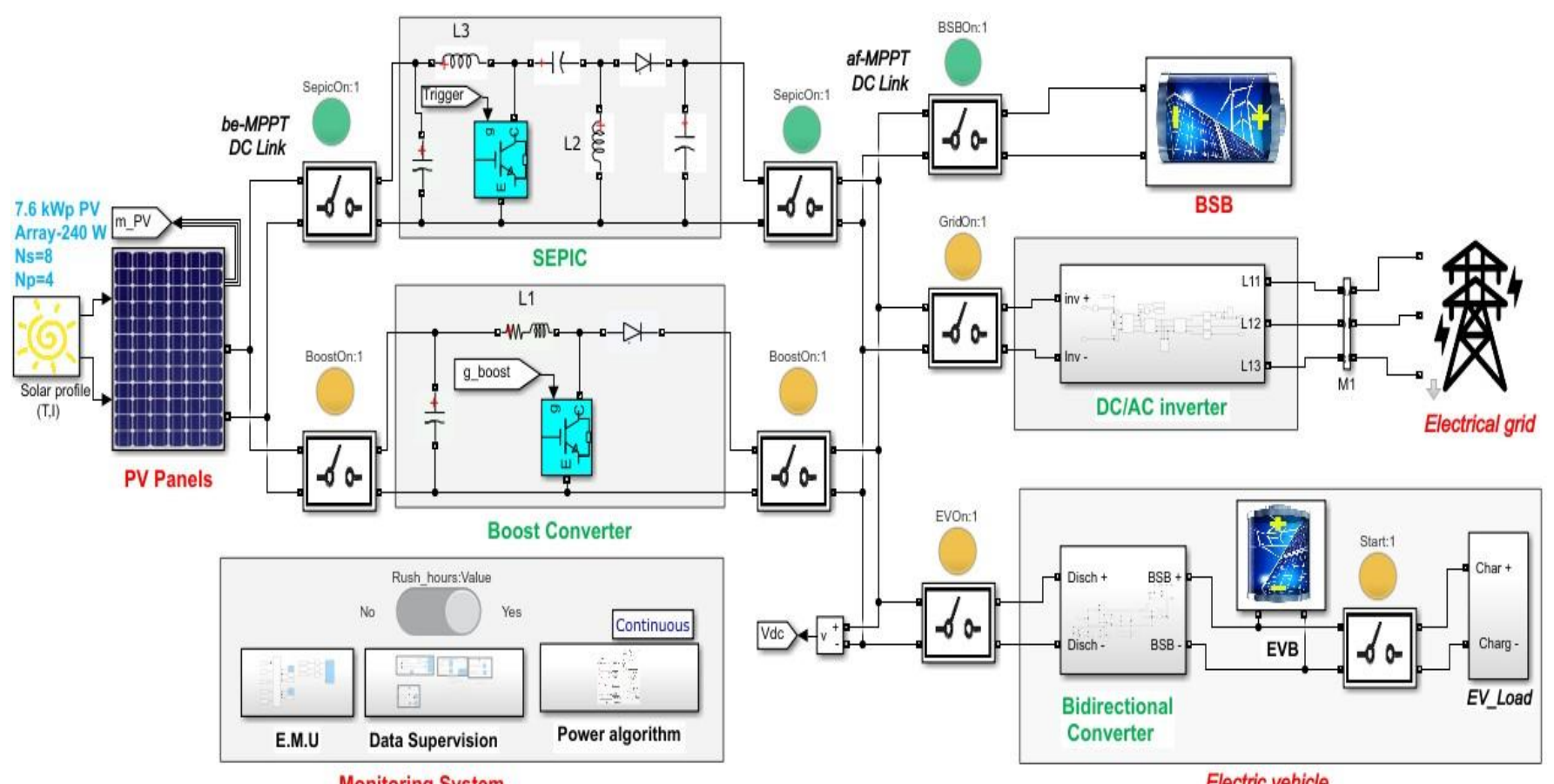

Fig 6. Proposed SCS Topology in Matlab/Simulink.

\section{A. Case-1: PV to BSB (Pv2B)}

During a sunny day with a high level of irradiation, the Pv2B mode is given high priority to gain from solar energy to load the CS battery (BSB). At this case, the battery charger is operated under one of the two modes of control, where numerous constraints are treated to ensure a reliable charging process. Fig. 7 shows the used timeline of a climatic scenario and the charging power injected into the BSB.

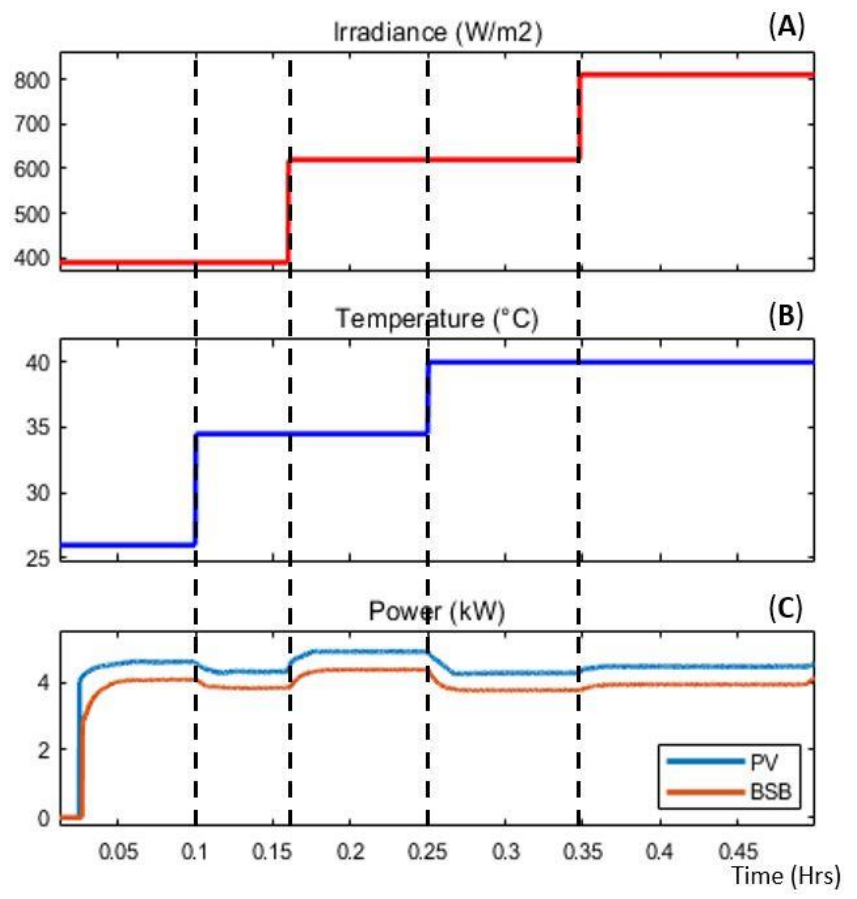

Fig 7. Curves of the Pv2B mode versus Time (A) Irradiation; (B) Temperature; (C) PV/BSB Power.
For $\mathrm{t}=0-0.1 \mathrm{Hrs}$, the system aims to extract the maximum power from $400 \mathrm{~W} / \mathrm{m}^{2} ; 26^{\circ} \mathrm{C}$. After $0.1 \mathrm{Hrs}$, the temperature is up to $34.7^{\circ} \mathrm{C}$ and as result, the PV power is decreased to $4.1 \mathrm{~kW}$, thus the temperature is inversely proportional to the generated power from solar array. In these circumstances, the system achieves an energy efficiency close to $92 \%$, in which the energy losses are mainly related to passive converter components. After $\mathrm{t}=0.16 \mathrm{Hrs}$, the irradiance is increased to $610 \mathrm{~W} / \mathrm{m}^{2}$, so the PV power is up to $4.6 \mathrm{~kW}$. Therefore, the power is proportional to the changes of solar irradiance. Besides, Fig. 8 shows the charging process of the BSB via current and SC curves.
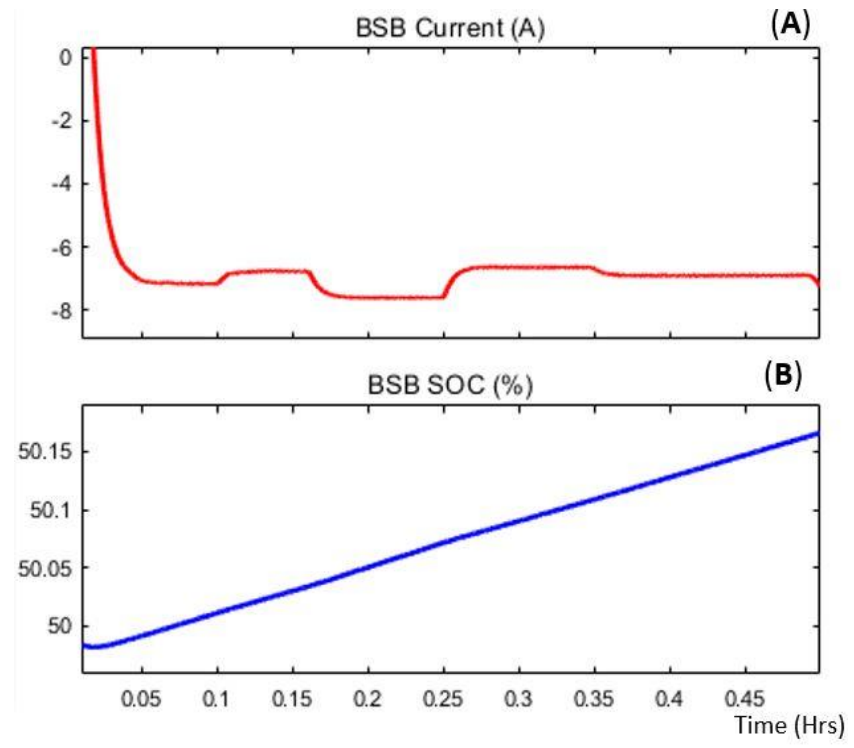

Fig 8. Curves of the BSB Charging Phase versus Time (A) Current; (B) SC. 
(A)

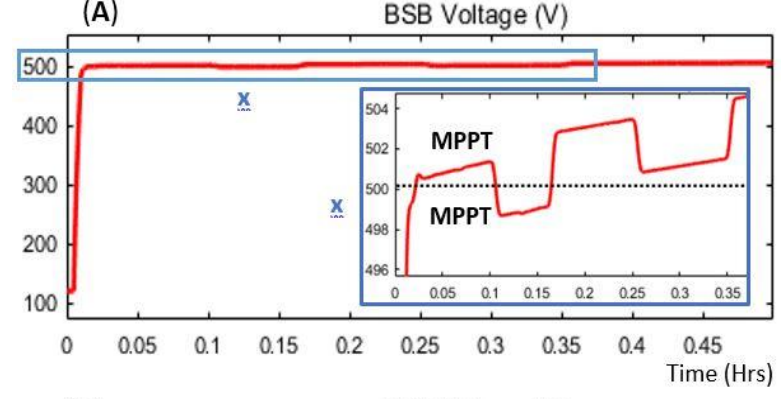

(B)

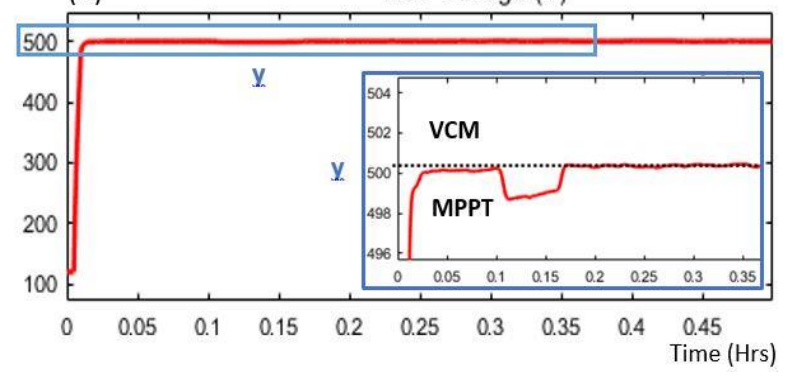

Fig 9. Curves of the BSB Charging Voltage versus Time (A) without CSMS; (B) with CSMS.

In this operating mode, the CSMS adds further complexities and constraints to the control strategy in order to achieve safety charging/discharging processes of the BSB. Therefore, the algorithm will avoid the depth of discharge state of the CS battery and to not operate it in the harmful phase of saturation. As it can be seen in the previous results, the changes of solar irradiation affect the curve slope of the BSB SC which is featured by its inclination rate, thus, the charging rate is not constant throughout the charging phase. However, Fig. 9 illustrates the results of the improved control strategy composed by voltage control mode and MPPT algorithm, each one of them is selected by the CSMS one at a time.

The Pv2B mode uses SEPIC as a battery charger of the BSB. The battery performance degradation is occurred when the charger output voltage surpasses the maximum rate of the BSB voltage, the MPPT algorithm control can cause this case scenario during the detection phase of the MPP as depicted in Fig. 9A. So, the management algorithm will fix the overloading dilemma during a charging phase of the battery as shown in Fig. 9B.

\section{B. Case-2: PV to Grid (Pv2G)}

Since electricity cannot be stored on a large scale, this mode is established to get more financial revenues for the CS owner based on RESs. Yet, the intermittent still very marked in the day/night alternation for solar power where this case is only possible in daylight. The electrical grid is equipped with an accurate mode of control to stabilize the injected power. So, the process is started with a dc/dc boost converter based MPPT algorithm, and a dc/ac inverter based VSC control. In order to maintain the DC link stable, the VSC is operated under Phaselocked loop (PLL), the loop system generates an output signal whose phase is related to the phase of a reference signal. However, Fig. 10 illustrates the injected power into the grid following the adopted climatic scenario.

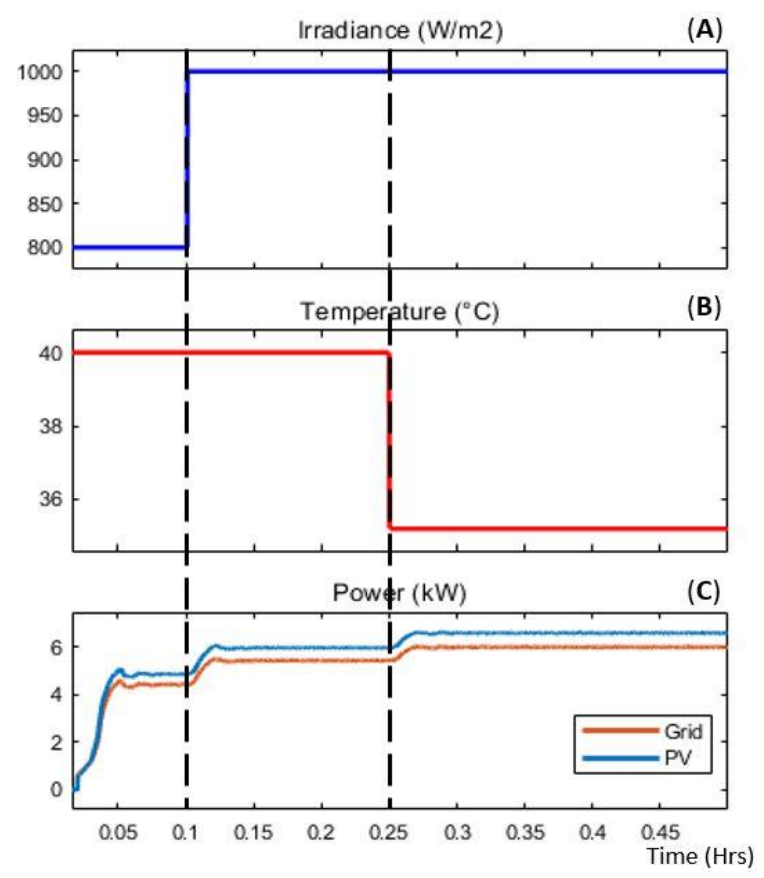

Fig 10. Curves of Pv2G Operating mode versus Time (A) Irradiation; (B) Temperature; (C) Power.

The VSC is composed by PLL followed by current regulator and PWM controller, the output is generated pulses sent to the inverter switches. During the simulation time, three different scenarios are tested on the PV system where high irradiation and low temperature made a best energy efficiency for the SCS.

\section{Case-3: Vehicle battery to Grid (V2G)}

The EVs can be plugged into the electrical grid via home or other bidirectional power slot. This work presents a study case of a small parking place equipped with multiple charging points, they have been provided with an $\mathrm{HCP}_{\mathrm{U}}$ so the customer could set his requirements in terms of power demand. A proposed $\mathrm{HCP}_{\mathrm{U}}$ data of three EVs is presented in Table I.

In order to apply the reference power on the bidirectional $\mathrm{dc} / \mathrm{dc}$ converter control with a quite level of efficiency, the private BMS of each EV will provide the CSMS with the required data form each EV user through the $\mathrm{HCP}_{\mathrm{U}}$. Fig. 11 and 12 show the curves of power, voltage and current of the grid versus the variations of data from the user control panel. The injected power into the grid is accordingly updated to each power scenario.

TABLE I. $\mathrm{HCP}_{\mathrm{U}}$ DATA OF THREE EVS OPERATED IN V2G OPERATING MODE

\begin{tabular}{|l|l|l|l|l|l|l|}
\hline EV & Brand & $\begin{array}{l}\text { Battery } \\
\text { Capacity } \\
(\mathbf{k W h})\end{array}$ & $\begin{array}{l}\text { Plugged } \\
\text { Time } \\
(\mathbf{H r s})\end{array}$ & $\begin{array}{l}\text { Initial } \\
\mathbf{S C} \\
(\mathbf{\%})\end{array}$ & $\begin{array}{l}\text { Final } \\
\mathbf{S C} \\
(\boldsymbol{\%})\end{array}$ & $\begin{array}{l}\text { EV } \\
\text { demand } \\
(\mathbf{k W})\end{array}$ \\
\hline $\mathbf{1}$ & $\begin{array}{l}\text { Nissan } \\
\text { Leaf 2 }\end{array}$ & 40 & 0.15 & 93 & 81 & 32 \\
\hline $\mathbf{2}$ & $\begin{array}{l}\text { Kia e- } \\
\text { Niro }\end{array}$ & 64 & 0.2 & 87 & 79 & 25.6 \\
\hline $\mathbf{3}$ & $\begin{array}{l}\text { Tesla } \\
\text { Model } \\
\text { X }\end{array}$ & 75 & 0.15 & 95 & 85 & 50 \\
\hline
\end{tabular}




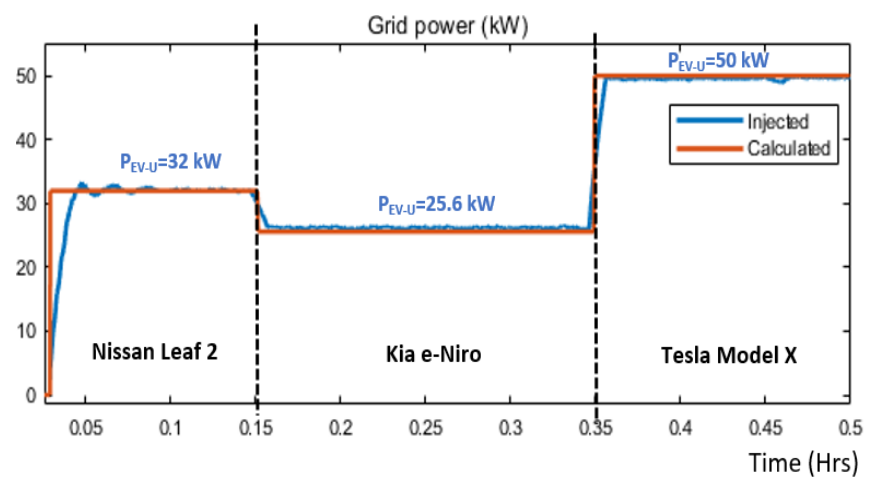

Fig 11. Curve of Grid Power versus Time.
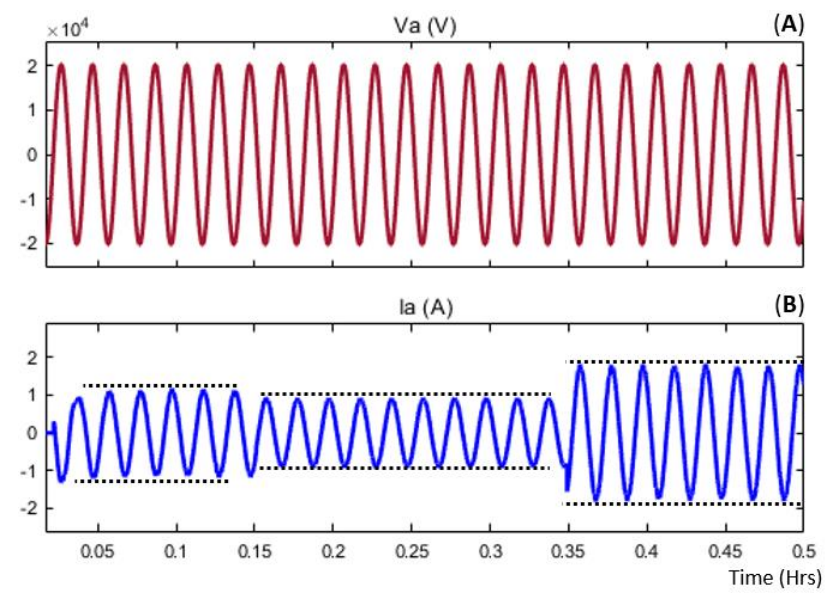

Fig 12. Grid Curves versus Time (A) Voltage; (B) Current.

In this mode, the bidirectional charger of the EV battery is operated in discharging mode, it is controlled by a current control mode based on PI block that regulates the stability, the rapidity and the accuracy of the discharging process.

\section{EXPERIMENTAL EVALUATION}

A laboratory prototype of the proposed topology is set to test the effectiveness of the control strategies. The PV output power is controlled by Texas instrument Solar Explorer Kit. It puts up a flexible low voltage platform to assess the C2000 microcontroller family for solar power applications. Fig. 13 illustrates the printed circuit board, in which the proposed control strategies will be verified.

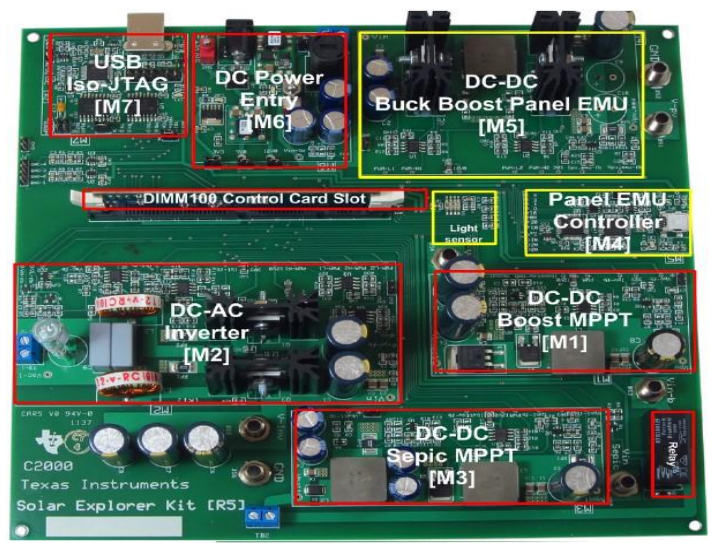

Fig 13. Macro Blocks of Solar Explorer Kit.

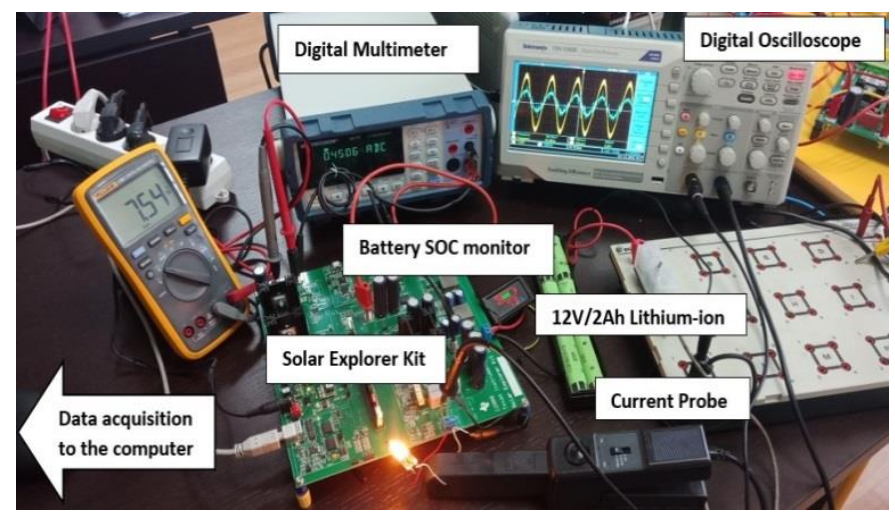

Fig 14. Experimental Prototype of the Solar Charging Station.

The circuit board consists of F28035 piccolo control card in order to drive the dc/dc boost converter, the SEPIC and the inverter. The PV array is emulated via a synchronous buck boost stage controlled by Piccolo-A F28027 card.

The prototype is set up to emulate the multiple stages of $\mathrm{dc} / \mathrm{dc}$ and of $\mathrm{dc} / \mathrm{ac}$ conversion along with a real-time processing to run the various kinds of control. A PV emulator is built onto the board with a buck/boost power stage using light sensor as data input. To complete the demonstration, a lithium-ion battery is used to perform the $12 \mathrm{~V} / 2 \mathrm{Ah} \mathrm{BSB}$. Fig. 14 shows the experimental prototype of the solar CS topology.

The PV-grid tied inverter uses a dc/dc boost converter operated at $100 \mathrm{kHz}$ to increase and to stabilize the output voltage at $30 \mathrm{~V}$ (af-MPPT DC link). The DC link voltage at the $\mathrm{dc} / \mathrm{ac}$ inverter input is required to be higher than the maximum AC voltage. Fig. 15 shows the curves of voltage and current at the inverter output stage operated at $20 \mathrm{kHz}$. As it can be seen, both the voltage and the current are set to be operated at the grid frequency $(50 \mathrm{~Hz})$. To highlight the control strategy of the injection mode, several modulation schemes are analyzed in order to feed current into the grid through a high frequency full bridge inverter. This control strategy is basically based on unipolar modulation used to switch alternate legs depending on which sine half of the AC signal is being generated. Fig. 16 illustrates the AC grid power. The inverter output is connected to LCL filter to improve the waveforms of grid voltage and current, thus the grid power in the channel $M$ (red) obtained 16.1VA.

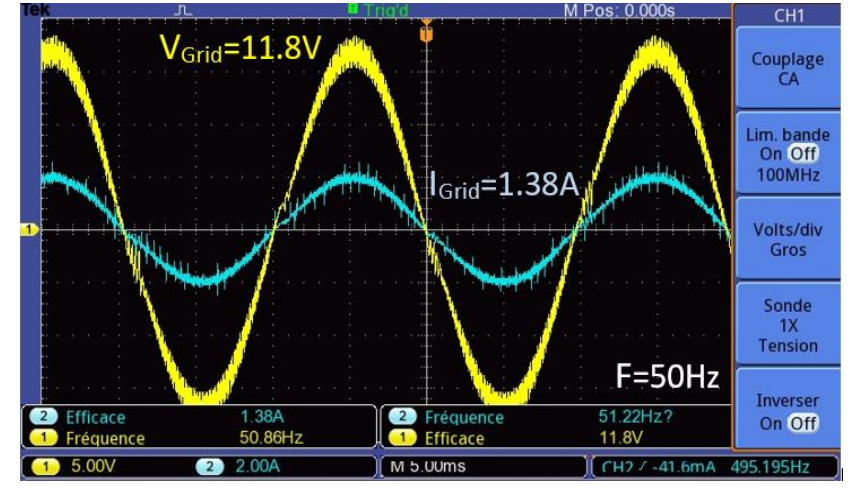

Fig 15. Experimental AC Voltage $(\mathrm{CH} 1)$ and $\mathrm{AC}$ Current $(\mathrm{CH} 2)$ at Grid side versus Time. 


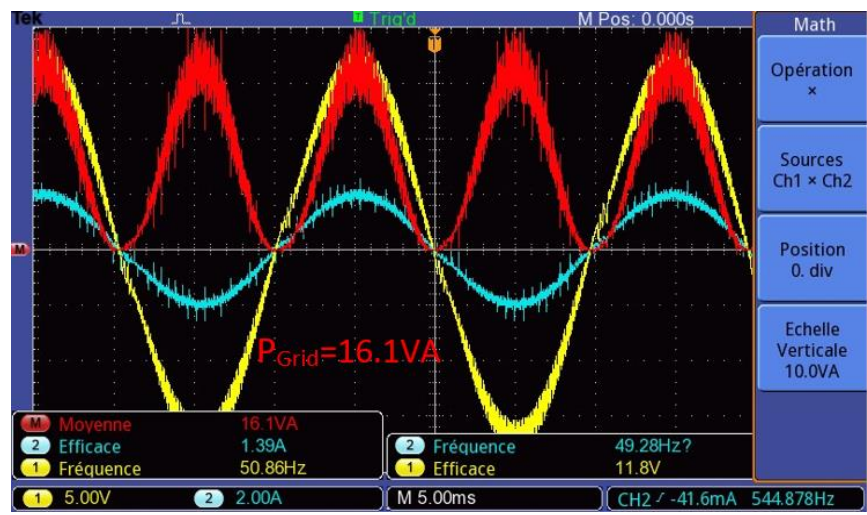

Fig 16. Experimental AC grid Power versus Time (CHM).

In this mode, a synchronous buck/boost stage is used to emulate the PV array, the input voltage is provided from a DC power block, where the kit is supplied by a 24V/2.5A. Fig. 17 and 18 show the experimental DC power, voltage and current at $0.5 \mathrm{~kW} / \mathrm{m}^{2}$ of irradiation.

At $0.5 \mathrm{~kW} / \mathrm{m}^{2}$, the $\mathrm{PV}$ emulator delivers $18.8 \mathrm{~W}$ and the power at the inverter output stage is 16.18VA. Further experiences are done under various luminance ratios in order to create concrete climatic scenarios. Table II summarizes the experimental results of the injection mode into the grid under various rates of irradiance $\left(0.2-1 \mathrm{~kW} / \mathrm{m}^{2}\right)$.

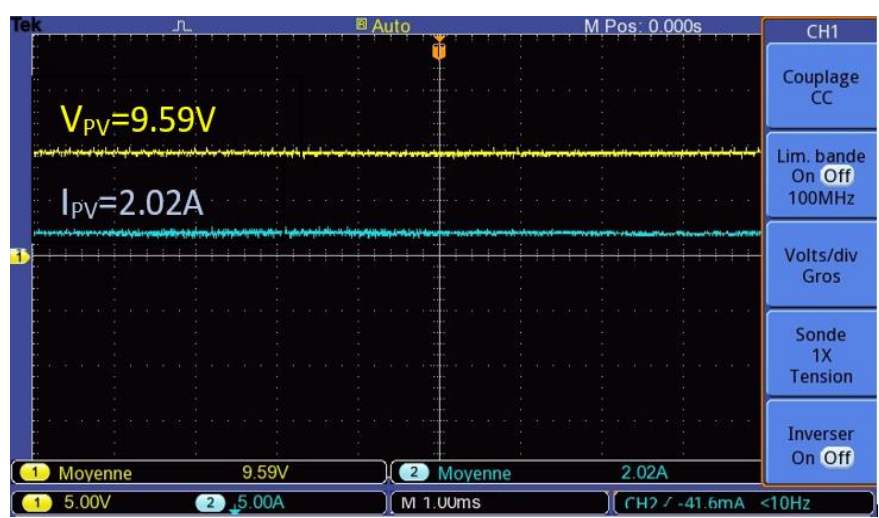

Fig 17. Experimental DC Voltage $(\mathrm{CH} 1)$ and Current $(\mathrm{CH} 2)$ versus Time at $0.5 \mathrm{~kW} / \mathrm{m}^{2}$

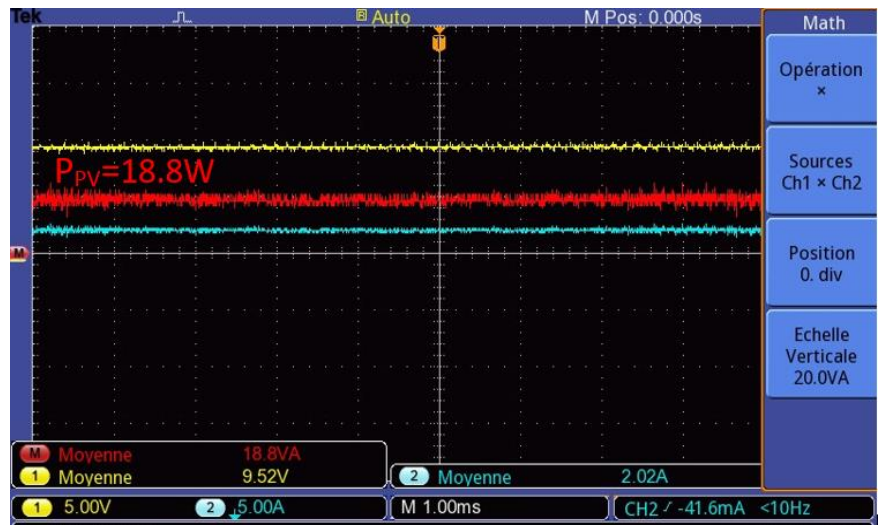

Fig 18. Experimental DC Power (Red) versus Time at $0.5 \mathrm{~kW} / \mathrm{m}^{2}$.
TABLE II $\quad$ EXPERIMENTAL RESULTS OF DIFFERENT RATIOS OF SOLAR IRRADIANCE

\begin{tabular}{|c|c|c|c|}
\hline $\begin{array}{c}\text { Luminance Ratio } \\
\left(\mathrm{kW} / \mathrm{m}^{2}\right)\end{array}$ & $\begin{array}{l}\text { Power at MPP } \\
\text { (Watts) }\end{array}$ & $\begin{array}{c}\text { Voltage at MPP } \\
\text { (Volts) }\end{array}$ & $\begin{array}{l}\text { Grid power } \\
\text { (VA) }\end{array}$ \\
\hline 1 & 36.02 & 18.46 & 33.17 \\
\hline 0.9 & 32.42 & 16.42 & 29.54 \\
\hline 0.8 & 28.82 & 14.68 & 25.95 \\
\hline 0.7 & 25.22 & 12.77 & 22.23 \\
\hline 0.6 & 21.61 & 10.98 & 18.81 \\
\hline 0.5 & 18.80 & 9.516 & 16.18 \\
\hline 0.4 & 14.41 & 7.363 & 12.29 \\
\hline 0.3 & 10.81 & 5.473 & 9.31 \\
\hline 0.2 & 7.205 & 3.67 & 6.23 \\
\hline
\end{tabular}

TABLE III. POWER STAge PARAMETERS OF THE SEPIC

\begin{tabular}{|c|c|c|c|c|c|}
\hline \multicolumn{2}{|c|}{ Voltage (V) } & \multicolumn{2}{c|}{ Current (A) } & Power rating & \multirow{2}{*}{$\begin{array}{c}\text { Frequency } \\
\text { max (WHz) }\end{array}$} \\
\cline { 1 - 3 } Input & Output & Input & Output & & 200 \\
\hline $0-30$ & $10-16$ & $0-3.5$ & $0-3.5$ & 50 & 200 \\
\hline
\end{tabular}

During the Pv2B operating mode, some precautions are established in order to get the system matched the required case scenario. Table III expresses the features of the allowed margin of the connected load.

A $12 \mathrm{~V} / 2 \mathrm{Ah}$ lithium-ion battery is chosen to test the $50 \mathrm{~W}$ PV emulator. However, the battery charger is operated under a hybrid strategy of control. Fig. 19 and 20 show the voltage, the current, and the power at the input and at the output of SEPIC at $0.2 \mathrm{~kW} / \mathrm{m}^{2}$.

As follows from the figures shown above, the SEPIC is operated at buck mode due to the low irradiance rate applied in the PV emulator input $\left(0.2 \mathrm{~kW} / \mathrm{m}^{2}\right)$. From the characteristics of the adopted battery, an overcharge voltage is fixed to $\mathrm{V}_{\mathrm{OC}}=15 \mathrm{~V}$, so the condition in which the CSMA would switch the control from MPPT algorithm to VCM is when the BSB voltage exceeds $0.95 \mathrm{~V}_{\mathrm{OC}}(14.25 \mathrm{~V})$, such case is depicted in Fig. 20, where $\mathrm{V}_{\mathrm{BAT}}$ still at $0.86 \mathrm{~V}_{\mathrm{OC}}(12.7 \mathrm{~V})$. In this case, the $\mathrm{dc} / \mathrm{dc}$ converter is controlled by MPPT algorithm.

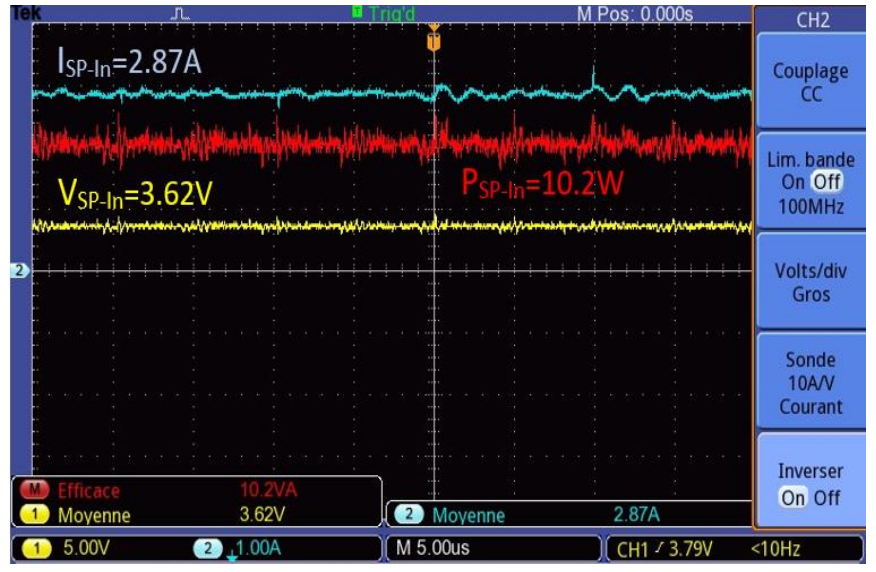

Fig 19. Experimental DC Voltage, Current and Power at SEPIC Input versus Time. 


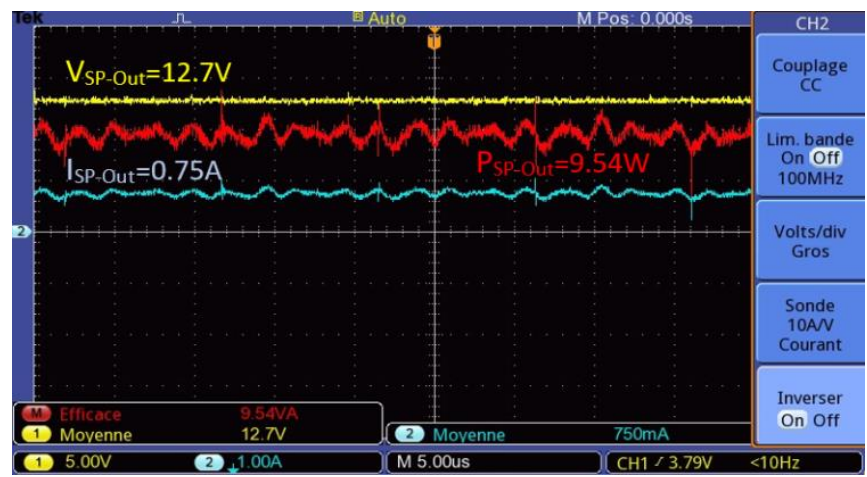

Fig 20. Experimental DC Voltage, Current and Power at SEPIC Output versus Time.

\section{CONCLUSION}

In this paper, a solar charging station for EVs is presented in detail to design and to analyze three power flow scenarios i.e., Pv2B, Pv2G and V2G. In order to maintain a high level of accuracy and stability of each operating mode, hybrid control strategies were validated by simulation and experimental tests. The reliability and the flexibility of this approach are achieved by a charging station management algorithm. From the proposed topology, the management algorithm is productive while considering some criteria, such as the capacity of the $\mathrm{BSB}$, the installed power of PV array, and of grid transformer.

The accuracy and the stability of each operation mode has been validated by simulation results of $7.68 \mathrm{~kW}$ power system performed in Matlab/Simulink. Thus the findings are analyzed with experimental evaluations using a low power solar kit. In terms of decreasing the charging cost from over-relying on the grid and for a smooth integration of eventual other renewable energy sources, this optimization approach obtained gainful outcomes. However, it is also important to analyse the economic and the reliability aspects of the proposed system based on hybrid energy sources, which can also be treated as the future scope of this work.

\section{REFERENCES}

[1] B. Dolter and N. Rivers, "The cost of decarbonizing the Canadian electricity system," Energy Policy, vol. 113, pp. 135-148, Feb. 2018.

[2] A. R. Bhatti, Z. Salam, M. J. B. A. Aziz, K. P. Yee, and R. H. Ashique, "Electric vehicles charging using photovoltaic: Status and technological review," Renewable and Sustainable Energy Reviews, vol. 54, pp. 3447, Feb. 2016

[3] H. Jakir, N. Sakib, E. Hossain and R. Bayindir, "Modelling and Simulation of Solar Plant and Storage System: A Step to Microgrid Technology," International Journal of Renewable Energy Research, vol. 7, no. 2, pp. 723-737, 2017.

[4] J. A. Domínguez-Navarro, R. Dufo-López, J. M. Yusta-Loyo, J. S. Artal-Sevil, and J. L. Bernal-Agustín, "Design of an electric vehicle fastcharging station with integration of renewable energy and storage systems," International Journal of Electrical Power \& Energy Systems, vol. 105, pp. 46-58, Feb. 2019.
[5] J. Lee and G.-L. Park, "Dual battery management for renewable energy integration in EV charging stations," Neurocomputing, vol. 148, pp. 181-186, Jan. 2015.

[6] I. A. Nienhueser and Y. Qiu, "Economic and environmental impacts of providing renewable energy for electric vehicle charging - A choice experiment study," Applied Energy, vol. 180, pp. 256-268, Oct. 2016.

[7] P. Goli and W. Shireen, "PV powered smart charging station for PHEVs," Renewable Energy, vol. 66, pp. 280-287, Jun. 2014.

[8] A. R. Bhatti, S. Zainal, J. B. A. A. Mohd and P. Y. Kong, "A Comprehensive Overview of Electric Vehicle Charging Using Renewable Energy," International Journal of Power Electronics and Drive Systems, vol. 7, no. 1, pp. 114-123, 2016.

[9] A. Hassoune, M. Khafallah, A. Mesbahi, L. Benaaouinate, and T. Bouragba, "Control Strategies of a Smart Topology of EVs Charging Station Based Grid Tied RES-Battery," International Review of Electrical Engineering (IREE), vol. 13, no. 5, pp. 385-396, Oct. 2018.

[10] H. Fathabadi, "Novel solar powered electric vehicle charging station with the capability of vehicle-to-grid," Solar Energy, vol. 142, pp. 136143, Jan. 2017.

[11] A. Luo, Q. Xu, F. Ma and Y. Chen, "Overview of power quality analysis and control technology for the smart grid," in Journal of Modern Power Systems and Clean Energy, vol. 4, no. 1, pp. 1-9, January 2016.

[12] Y. Cheddadi, F. Errahimi, and N. Es-sbai, "Design and verification of photovoltaic MPPT algorithm as an automotive-based embedded software," Solar Energy, vol. 171, pp. 414-425, Sep. 2018.

[13] Y. Aljarhizi, A. Hassoune, and E. M. Al Ibrahmi, “Control Management System of a Lithium-ion Battery Charger Based MPPT algorithm and Voltage Control," 2019 5th International Conference on Optimization and Applications (ICOA), Apr. 2019.

[14] R. Bradai, R. Boukenoui, A. Kheldoun, H. Salhi, M. Ghanes, J.-P. Barbot, and A. Mellit, "Experimental assessment of new fast MPPT algorithm for PV systems under non-uniform irradiance conditions," Applied Energy, vol. 199, pp. 416-429, Aug. 2017.

[15] J. P. Torreglosa, P. García-Triviño, L. M. Fernández-Ramirez, and F. Jurado, "Decentralized energy management strategy based on predictive controllers for a medium voltage direct current photovoltaic electric vehicle charging station," Energy Conversion and Management, vol. 108, pp. 1-13, Jan. 2016.

[16] J. Caballero, J. Chinchilla, and J. Rosero Garcia, "Performance Testing and Power Quality of DC Semi-Fast Chargers of Electric Vehicles (EVs) for Public Transportation: A Case Study," International Review of Electrical Engineering (IREE), vol. 11, no. 6, pp. 579, Dec. 2016.

[17] A. Hassoune, M. Khafallah, A. Mesbahi, and T. Bouragba, "Power Management Strategies of Electric Vehicle Charging Station Based Grid Tied PV-Battery System," International Journal of Renewable Energy Research (IJRER), vol. 8, no. 2, pp. 851-860, Jun. 2018.

[18] S. Chalise, J. Sternhagen, T. M. Hansen, and R. Tonkoski, "Energy management of remote microgrids considering battery lifetime," The Electricity Journal, vol. 29, no. 6, pp. 1-10, Jul. 2016.

[19] A. Mendoza-Torres, N. Visairo, C. Nuñez, J. Armenta, E. Rodríguez, and I. Cervantes, "Switching rule for a bidirectional DC/DC converter in an electric vehicle," Control Engineering Practice, vol. 82, pp. 108-117, Jan. 2019.

[20] W. Wojtkowski, "Digital control of a bidirectional DC / DC converter for automotive applications," IFAC-PapersOnLine, vol. 51, no. 6, pp. 113-118, 2018.

[21] A. Hassoune, M. Khafallah, A. Mesbahi, and T. Bouragba, "An Improved Approach of Control for a Battery Charger Based Forward Converter and SEPIC," 2018 6th International Renewable and Sustainable Energy Conference (IRSEC), Dec. 2018. 